\title{
DESARTICULAÇÕES ENTRE POLÍTICAS URBANAS E INVESTIMENTOS EM CIDADES: contratação do PAC paraense
}

\author{
mismatches between urban policies and investments in cities: \\ the negotiation of PAC in Pará State, Brazil
}

Ana Cláudia Duarte Cardoso*

\begin{abstract}
Resumo
Este texto discute a correspondência entre os objetivos da Política Nacional de Desenvolvimento Urbano (PNDU) e a racionalidade de investimentos do Programa de Aceleração do Crescimento (PAC), com foco no eixo Infraestrutura Social e Urbana. Sua argumentação é construída a partir das especificidades da cidade brasileira, do modo como políticas urbanas são formuladas participativamente e operadas através de um banco social, da discussão do papel econômico da habitação e infraestrutura urbana e da sua adoção no Brasil como ferramenta de desenvolvimento. Através de um caso concreto, as contratações realizadas pelo Governo do Estado do Pará, o texto apresenta os desafios ao acesso e à operação dos investimentos da primeira geração do PAC. Após quatro anos do início do processo, sugere uma avaliação e constata a necessidade de aproximação entre as concepções de investimentos e da PNDU, e sugere também uma agenda que contemple desde a incorporação de tendências de inserção das cidades brasileiras em seus respectivos contextos regionais até mudanças nas estratégias de operação das políticas urbanas em questão.
\end{abstract}

Palavras-chave: Política Nacional de Desenvolvimento Urbano, Programa de Aceleração do Crescimento, Programa Minha Casa Minha Vida, Programas habitacionais.

\begin{abstract}
This article discusses the correspondence between Urban Development National Policy (PNDU) declared aims and the rationality of Acceleration of Growth Program (PAC) investments, directed to urban and social infrastructure. It unfolds from ideas such as Brazilian cities specificities, the participative formulation of urban policies and its operation through a social bank, and the discussion of economic roles of housing and urban infrastructure and its adoption as a tool for development in Brazil. It takes a real case, Pará State Government contracts, to present contradictions and challenges of PAC's first generation of investments, and after four years from the beginning of the process, it suggests assessments, the need of approaching investment's and PNDU's conceptions, and an agenda with coverage ranging from trends related to insertion of Brazilian cities in their regional contexts, up to changes in operation strategies of the urban policies under analysis.
\end{abstract}

Key words: Brazilian National Urban Development Policy; Acceleration Growth Program, My House My Life Program, Housing Programs.

\section{Resumen}

Este artículo es una discusión sobre la correlación entre los objetivos de la Política Nacional de Desarrollo Urbano (PNDU) y la racionalidad de las inversiones del Programa de Aceleración del Crecimiento (PAC), centrado en el eje Infraestructura Social y Urbana. Su argumento es construido a partir de: las características específicas de la ciudad brasileña, la forma en la cual las políticas urbanas están formulados de manera participativa y operadas a través de un banco social, de la discusión del papel económico de la vivienda y de la infraestructura urbana y su adopción en Brasil como una herramienta de desarrollo. A través de un caso concreto, los contratos realizados por el Gobierno del Estado del Pará, el artículo presenta los retos de la contratación y gestión de las inversiones de la primera generación del PAC y, cuatro años después del inicio del proceso, sugiere una evaluación y la necesidad de acercamiento entre los conceptos de la inversión y el PNUD. Sugiere también una agenda que incluye desde la incorporación de las tendencias de la inserción de las ciudades brasileñas en sus respectivos contextos regionales hasta los cambios en las estrategias de operación de las políticas urbanas en cuestión.

Palabras clave: Programa Nacional de Desarrollo Urbano, Programa de Aceleración del Crecimiento, Programa Mi Casa Mi Vida, Programas de Vivienda

(*) Bolsista Produtividade do CNPq, Prof ${ }^{a}$. Dra . da Universidade Federal do Pará, - Instituto de Tecnologia, Campus do Guamá, Rua Augusto Correia, s/n - Guamá, CEP: 66.075-110 - Belem (PA) - Brasil - Tél: (+ 55 91) 3201-7000 - aclaudiacardoso@ gmail.com 


\section{INTRODUÇÃO}

A cidade brasileira tem uma trajetória peculiar, bastante diferente de sua contraparte europeia. Enquanto a segunda floresceu e se consolidou a partir da produção artesanal, do comércio e principalmente da industrialização; a cidade brasileira foi criada como base da burocracia e apoio ao domínio militar do território. Durante séculos as funções administrativas e políticas sobrepujavam a função econômica, uma vez que o poder econômico era concentrado no campo. A difusão da cidade comercial ocorreu apenas quando a capacidade da produção rural gerou um excedente comercializável capaz de atender às necessidades de consumo externas. Apenas com a vinda da família real, há dois séculos, houve uma diversificação de classes sociais urbanas e a consolidação de novas atividades de comércio e serviço. Contudo as novas elites demandaram importações antes que as iniciativas de artesanato local evoluíssem para a produção industrial. No início do século XX, as cidades cresceram com a chegada de migrantes, negros libertos, camponeses e estrangeiros, os quais constituíram um proletariado importante para a criação de mercado consumidor, mas que desde então estiveram mal alojados e excluídos de muitas dimensões da vida nas cidades (SINGER,1973; MARICATO, 2001).

$\mathrm{O}$ século $\mathrm{XX}$ assistiu à transformação do Brasil em um país desenvolvimentista, onde as estratégias de desenvolvimento econômico, concentrado nas regiões sudeste e sul do país, assumiram caráter prioritário na gestão federal; entretanto, como reverso do processo, todas as heranças históricas de desigualdade foram agravadas, e manifestas em todas as regiões e escalas territoriais (JATOBÁ, 1979). O crescimento das cidades e a posterior constituição de regiões metropolitanas, explicitaram a necessidade de políticas sociais voltadas para o acesso à terra urbanizada, à moradia, e à vida nas cidades. A dinâmica metropolitana inspirou meio século de mobilização de profissionais e movimentos sociais e apresentou diversos resultados positivos, como o significativo avanço ocorrido na política habitacional brasileira. Foram marcos dessa evolução tanto a massificação da produção habitacional através do Banco Nacional de Habitação - BNH, ocorrida nos anos 1970 e 1980, quanto a recente constituição de um Sistema Nacional de Habitação de Interesse Social em 2005, com a missão de estruturar uma política voltada para a produção subsidiada de habitação para os segmentos sociais que sempre estiveram excluídos (RIBEIRO, CARDOSO, 2003; VALENÇA, BONATE 2010; CARDOSO, 2008).

$\mathrm{Na}$ área do desenvolvimento urbano, um marco importante foi a inclusão do capítulo sobre a reforma urbana na Constituição Federal de 1988, e o Estatuto da Cidade oferecendo um arcabouço legal voltado para o reconhecimento da função social da cidade. A criação do Ministério das Cidades e a adoção de estratégias participativas para a formulação de suas políticas são outro marco importante. O Conselho das Cidades permitiu que representantes de todos os estados do país trouxessem para um conselho nacional a voz de representantes de todos os municípios que realizaram suas conferências das cidades, enfatizando a gestão democrática e o avanço nas políticas setoriais diretamente vinculadas à cidade (BRASIL, 2010). Outros debates sobre os problemas urbanos revelam necessidades de articulação entre escalas (regional, sub-regional, local, ou, urbano, periurbano e rural) e entre áreas de conhecimento (saberes sociais, tecnológicos, ambientais, legais), fomentando interlocuções ainda não estruturadas em municípios das regiões periféricas do país (Norte e Nordeste) (MIRANDA et al., 2010).

Ressalvamos que todas essas conquistas estão relacionadas a problemas, e debates acalorados, exaustivamente estudados por autores, tais como Bonduki (1998), Carpintéro (1997), Rolnik (1997), Valença (2003), Valença e Bonates (2010), cujo resgate não é necessário para o escopo deste artigo. Apenas os marcos dos avanços são apontados aqui para pautar uma trajetória que precisa ser lembrada para facilitar a compreensão de seu momento presente, onde coexistem formulações de novas políticas de desenvolvimento urbano, de habitação e saneamento, com investimentos vinculados a programas federais, tais como o Programa de Aceleração do Crescimento e o Minha Casa Minha Vida.

Em que pese a autonomia de estados e municípios, o elevado volume de recursos necessários para investimentos nessas áreas, associado à baixa capacidade financeira municipal, faz com que 
ocorra na prática uma indução da ação desses entes federados pela União, mediante adesão aos sistemas federais (ARRETCHE, 2004). Geralmente os sistemas propostos a partir do Ministério das Cidades foram concebidos a partir de intenso debate técnico e social, reconhecendo o protagonismo federal sem esquecer a diversidade das realidades geográficas, socioculturais e ambientais brasileiras. Como exemplo disso citamos a construção do Plano Nacional de Habitação, que adotou 11 tipologias municipais, e fomentou o desenvolvimento de planos estaduais e municipais para habitação de interesse social, tendo em vista a proposição de planos de ação para o setor de acordo com as diferentes realidades manifestas no país (BRASIL, 2009).

Outros estudos foram realizados para compreender a diversidade urbana brasileira, destacando-se o estudo de Tipologia de Cidades, que identificou 19 classes de municípios a partir de sua inserção regional (BRASIL, 2008). Muito dessa efervescência contribuiu para propostas de políticas públicas comprometidas com o enfrentamento do passivo histórico de desigualdade e precariedade imposto às cidades em geral, e particularmente às periferias das cidades brasileiras.

Uma evidência dessa intenção é o conceito de desenvolvimento urbano apresentado pelo Ministério das Cidades aos delegados da II Conferência Nacional das Cidades em 2005, e publicado do "Caderno 1" daquele Ministério:

Podemos definir o desenvolvimento urbano como a melhoria das condições materiais e subjetivas de vida nas cidades, com diminuição da desigualdade social e garantia de sustentabilidade ambiental, social e econômica. Ao lado da dimensão quantitativa da infra-estrutura, dos serviços e dos equipamentos urbanos, o desenvolvimento urbano envolve também uma ampliação da expressão social, cultural e política do indivíduo e da coletividade, em contraponto aos preconceitos, a segregação, a discriminação, ao clientelismo e a cooptação.

O objeto de uma política de desenvolvimento urbano é o espaço socialmente cons $\neg$ truído. Não estamos tratando das políticas sociais, de um modo geral, mas daquelas que estão relacionadas ao ambiente urbano. Considerando esse tema, um novo recorte torna mais objetivo o escopo do trabalho em torno dos temas estruturadores do espaço urbano e de maior impacto na vida da população: habitação, saneamento ambiental e mobilidade urbana e trânsito. Dois temas estratégicos se somam a este conjunto: a polí $\neg$ tica fundiária / imobiliária e a política de capacitação / informações" (BRASIL, 2004:8).

O tema do desenvolvimento urbano tornou-se demasiadamente abrangente para as estruturas administrativas o gerirem de forma bem coordenada no curto prazo, devido à natureza híbrida do espaço construído, estruturado a partir das estratégias do mercado de terra, e de necessidades socioculturais, condições ambientais, tecnológicas, paradigma político, etc.. A possibilidade de condução plenamente democrática do processo decisório a respeito de expansão e consolidação urbanas, por pactuação das múltiplas agendas envolvidas no âmbito dos conselhos das cidades (nacional, estaduais e municipais), concorre com as estratégias do mercado fundiário e imobiliário, e é limitada pelas possibilidades institucionais existentes para realização de investimentos que materializam os objetivos das políticas urbanas.

As possibilidades institucionais englobam desde a vontade política, a efetiva disponibilidade de recursos e de áreas para a produção de moradia, para a provisão de infraestrutura e de equipamentos comunitários, até a capacidade de diagnóstico e desenvolvimento de projetos adequados para as situações encontradas, de aprovação desses projetos em todas as instâncias competentes, de realização de certames licitatórios bem-sucedidos e em conformidade com a legislação federal, e da capacidade de monitoramento e correção de curso no decorrer da execução da obra. São tantas as instâncias a serem observadas até que um investimento seja concluído e responda aos objetivos da política ou programa que o gerou que todo um aparato institucional é criado para acompanhar os ritos, e na medida em que os investimentos ocorrem de fato, as lacunas, dificuldades e obstáculos vão-se revelando. 
Um laboratório muito interessante foi criado a partir da operação das ações vinculadas ao Projeto Prioritário de Investimentos - PPI, de intervenção em favelas, criado em 2006, e mais tarde transformado em carro chefe do PAC, quando os proponentes - estados e municípios - viram-se com a responsabilidade de conceber intervenções e projetos para áreas já ocupadas, e portanto sujeitas a um debate com os futuros beneficiários. A rigidez inerente à tradição brasileira de elaboração de projetos executivos de arquitetura, engenharia e urbanismo necessários para a efetivação dos contratos e liberação de recursos, somada à dificuldade de articular o curto tempo político para a elaboração de propostas, com o tempo que seria necessário para a construção democrática das mesmas, geraram frustração dentre as pessoas que esperavam ver os objetivos da PNDU alcançados .

No caso do PPI, a primeira contradição foi a própria seleção das áreas; o governo federal definiu que seriam elegíveis municípios com mais de 150 mil habitantes, os casos de obras inconclusas do Programa Habitar- Brasil BID ou de outros investimentos federais, e onde existissem palafitas em áreas urbanas. A tomada de decisão para além desses critérios foi deixada a cargo dos proponentes. No caso do Governo do Estado do Pará, a inexistência de diagnósticos que apontassem as prioridades de investimento foi resolvida através da seleção de áreas que melhor atendiam aos parâmetros de enquadramento do PPI, onde a Companhia Estadual de Habitação já dispunha de terras, ou nas adjacências de empreendimentos já concluídos, áreas que contassem com algum estudo preliminar de intervenção, e onde houvesse demanda popular.

Bastou o início das audiências públicas para que as comunidades percebessem as diferenças entre o produto oferecido e as expectativas coletivas. Muitas vezes o que a população pressupunha possível infringia a legislação ambiental ou comprometia soluções de saneamento, ou era inviável frente aos recursos disponíveis. O predomínio da visão da ação como uma obra, em que o cronograma de engenharia era mais importante para a liberação de recursos que o trabalho social, foi agravado pela grande dificuldade de contratação de equipes de profissionais para atuar nas frentes de licenciamento ambiental e condução do trabalho social, revelando que na prática a teoria era bem diferente . Neste quadro, a ação do setor público mostra-se, quando observada a partir de uma visão de curto prazo, fragmentada, desarticulada, distante da expectativa colocada por objetivos como os da PNDU.

\section{A OPERAÇÃO RECENTE DE RECURSOS DAS POLÍTICAS URBANAS BRASILEIRAS}

Uma chave para a compreensão das distâncias entre teoria e prática está na operação dos recursos que devem materializar as políticas urbanas. Com o fechamento do BNH, em 1986, as atribuições de operação das políticas urbanas em geral foram repassadas para a Caixa Econômica Federal, único banco público do país, que atua como banco comercial, no atendimento de pessoas físicas e pessoas jurídicas; e como banco social, através das frentes de desenvolvimento social (gestão de benefícios sociais e loterias), e desenvolvimento urbano, operando recursos a serem investidos na produção de habitação, saneamento, provisão de infraestrutura, e no apoio à gestão pública. A Caixa é o braço operador do Ministério das Cidades, e segue metas quantitativas de ampliação de contratações e atendimento da população. Seus contratos estão sujeitos aos controles do Ministério Público, do Tribunal de Contas da União e da Controladoria Geral da União, quanto à salvaguarda dos recursos públicos. O TCU considera a Caixa executante dos contratos, responsável por problemas inclusive de projeto, tanto quanto os órgãos estaduais e municipais responsáveis pelas obras.

A Caixa assumiu a operação dos grandes contratos de saneamento e habitação do FGTS herdados do BNH, e a partir de 1996 passou a gerenciar recursos do Orçamento Geral da União, contratados através de emendas parlamentares, para modificar a dinâmica dos convênios de repasse gerados entre união e municípios. Esses consistiam em depósito em conta corrente mediante uma única medição de acompanhamento e avaliação final e que vez por outra traduzia-se em obras fantasmas ou superfaturamento. Na época o Ministério da Integração inaugurou o novo sistema, em que a 
Caixa se tornou uma espécie de órgão auditor, sem ter poderes legais para tanto, mas realizando uma mediação, em geral, incômoda para os prefeitos .

Até 2000 o setor encarregado de operar tais contratos chamava-se ENGER (Setor de Engenharia), e era constituído prioritariamente por engenheiros, indicando a prevalência da obra em si na concepção de desenvolvimento urbano adotada pela instituição. Em 2000 foram criadas as Gerências de Desenvolvimento Urbano, vinculadas à Vice-Presidência de Governo - VIGOV, com um foco multidisciplinar. Por muito tempo este segmento da instituição foi tomado como deficitário, até que todos os desdobramentos dos seus contratos foram rastreados na área comercial, e houve a constatação de que, ao contrário do que se imaginava, o volume de recursos movimentados a partir das operações de desenvolvimento urbano ampliava as operações comerciais do banco. Em agosto de 2010, a VIGOV assumiu além dos investimentos, todos os contratos sociais do governo que antes eram abrigados em outros setores do Executivo, após o que cada setor de atuação passou a contar com uma superintendência em Brasília. Nas capitais as gerências foram transformadas em unidades da Rede de Sustentação de Negócios e Governo, chamadas RSGOVs, que mantiveram o foco da multidisciplinaridade. A quantidade de contratos e o volume de recursos sob responsabilidade desta área da Caixa aumentaram muito, a partir de 2005, assim como o rigor dos órgãos de controle, que acionam os técnicos da Caixa ou de órgãos públicos contratantes de recursos como pessoa física, quando há suspeita de irregularidade nos processos de aprovação e acompanhamento dos contratos, deixando claro que além de conhecimentos técnicos, são necessários aos técnicos conhecimentos de administração pública.

A aprovação de projetos que anteriormente dependia de análise de engenharia focada nos custos e quantitativos de projeto, passou a contar com uma avaliação jurídica que analisa documentação fundiária, contratos e licenciamentos; e com uma instância de avaliação social, para aprovação de projeto técnico-social e monitoramento da utilização do percentual de recursos da obra a ser investido na sua implementação, nos casos aplicáveis. Muitas vezes não há regulamentação urbanística local ou critérios claros aplicáveis às propostas de grandes empreendimentos, ensejando momentos de decisão pessoal do técnico encarregado da análise que, quando correta, será a única posição técnica a ser apresentada em todo o processo, e quando incorreta ou mal intencionada poderá favorecer o interesse particular em detrimento do interesse coletivo. Na prática, com a lenta renovação de quadros, em alguns estados observa-se o sentimento dos engenheiros de que os profissionais da área social estejam atrapalhando o processo, além disso, o aumento da complexidade dos contratos e do volume de recursos não foi acompanhado pelo aumento de pessoal em termos quantitativos e qualitativos, e a percepção do público externo é de que a Caixa emperra as contratações com sua sistemática de aprovação (figura 1).

Aparentemente, o ritmo acelerado de mudança na condução das políticas urbanas e de investimentos deslanchados sobrecarregou a estrutura administrativa disponível para sua operação no governo federal. A criação recente do Ministério das Cidades ainda não permitiu o amadurecimento de sua estrutura, para a proposição e articulação necessárias ao enfrentamento do passivo acumulado nas cidades brasileiras. Há muitas lacunas na regulamentação urbanística municipal, especialmente fora do ambiente metropolitano, quando comparadas ao crescente rigor das instâncias de controle administrativo e ambiental. Por outro lado, o papel dos governos estaduais permanece ambíguo, muitas vezes concorrendo com municípios na execução de obras, e deixando em segundo plano as funções de coordenação entre entes federados e setores de política pública, e de formulação (produção de diagnósticos, de planos, diretrizes sub-regionais, legislação).

É muito provável que haja espaço para a criação de novas instituições que possam se ater especificamente ao equacionamento dos pontos descobertos nas legislações federais, estaduais e municipais, e oferecer parâmetros de operação mais completos para agentes de operação como a Caixa, na direção do que faz, por exemplo, a Comissão para Arquitetura e Ambiente Construído da Grã-Bretanha (em inglês $\mathrm{CABE}$ ), pois a retomada de investimentos e o incentivo à produção habitacional, a partir do setor privado, explicitam que não é apenas dinheiro o problema, a qualidade 
de projetos desponta como desafio de grande impacto sobre as cidades, seguido pela disponibilidade de novos materiais e tecnologias capazes de responder a necessidades de custo, mas também a um melhor desempenho social e ambiental. A experiência demonstra que há espaço para mais regulamentação, e que uma regulamentação atenta à diversidade manifesta no território nacional reduzirá o improviso, o erro ou a corrupção no emprego de recursos públicos.

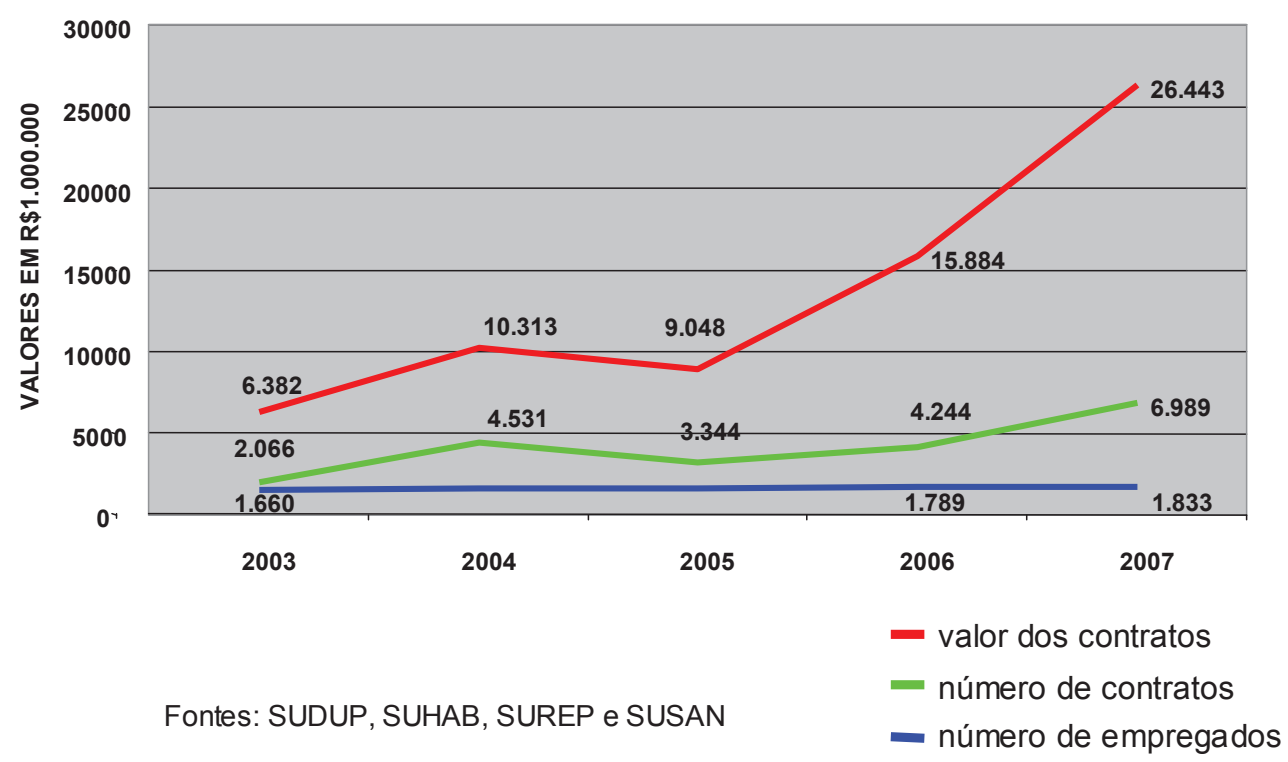

Figura 1 - Gráfico de evolução de número de empregados contratados, número e valor de contratos, no âmbito das Gerências Regionais da Caixa.

Fonte: Universidade Corporativa da Caixa, 2007.

\section{O PAPEL ECONÔMICO DO INVESTIMENTO EM HABITAÇÃO E INFRAESTRUTURA}

A associação da produção habitacional ao fomento do desenvolvimento é outro ponto fundamental, que se apresenta como justificativa à abertura de brechas e exceções em política urbanas. A necessidade de adoção de medidas anticíclicas em períodos de crise do capitalismo, capazes de preservar empregos e compensar as fugas de capital estrangeiro, destaca a indústria da construção civil como um setor estratégico desde a Inglaterra do século XIX. Nas primeiras décadas do século XX, aspectos político ideológicos deram sustentação para a difusão da casa própria como um bem que deveria ser garantido ao trabalhador pelo Estado (HALL, 1995).

Em meados do século XX, quando os países industrializados controlaram seus déficits habitacionais, garantiram condições de segurança contra incêndio e de salubridade para suas populações, e articularam a produção habitacional a soluções de transporte, a habitação passou a ser vista como um encargo social, muito caro para ser viabilizado através de subsídios nos países ainda em desenvolvimento. As recomendações econômicas advindas desse paradigma instituíram a permissividade para com a produção de assentamentos informais, tomados como solução "provisória" de habitação, que não desviava recursos produtivos para a melhoria de condições de reprodução do capital (TIBAIJUKA, 2009).

Apenas na década de 1960, através da atuação do BNH, o Brasil efetivou a utilização da habitação como ferramenta de desenvolvimento econômico, em meio a um período autoritário, quando era mais provável a interlocução dos segmentos da indústria da construção civil com governo, do que a interlocução entre sociedade e governo. Embora importante, a produção desse período foi insuficiente e inadequada se confrontarmos o perfil do segmento social em que reside a maior demanda, população com renda de 0 a 3 salários mínimos, e o produto oferecido (VALENÇA, 
BONATES, 2010; MARICATO, 2001).

Nesse período os programas executados consolidaram a competência e o capital das grandes empreiteiras brasileiras através da construção de grandes obras civis e de conjuntos com milhares de unidades habitacionais. Estes, construídos em áreas afastadas, mal servidas por equipamentos e serviços urbanos, serviram de âncoras para a consolidação de áreas de expansão, no decorrer de algumas décadas, adensadas tanto pelos investimentos do setor privado, quanto pela ocupação dos interstícios dos empreendimentos formais pelos grupos sociais excluídos (IPEA, 2001, MARICATO, 2002). A observação empírica indica que diversas cidades brasileiras tiveram porções estruturadas a partir dos conjuntos produzidos pelo $\mathrm{BNH}$, via Institutos de Orientação às Cooperativas Habitacionais - Inocoops, e companhias oficiais de habitação, uma vez que, aparentemente, por força de interesses e restrições diversas, as prefeituras careciam de outra estratégia técnica de organização global das cidades naquele período.

Após altos e baixos nos volumes de investimentos na produção de habitação (figura 2), observamos que a década de 2000 constituiu-se em um período de expansão de investimentos. $\mathrm{Na}$ segunda gestão do presidente Lula, e mais intensamente a partir da crise nas bolsas de valores de todo o mundo ocorrida em 2008, a construção civil assumiu mais uma vez a condição de ferramenta anti-cíclica, agora superposta à construção democrática de plataformas para políticas urbanas, e que avançava na elaboração de Planos Diretores Municipais Participativos, do Plano Nacional de Habitação - PlanHab, na consolidação da implantação do Sistema Nacional de Habitação de Interesse Social - SNHIS, e do próprio Conselho das Cidades. Tal superposição explicitou diversas contradições existentes no âmbito da política, do Ministério das Cidades e da relação entre governo federal e demais entes federados, exacerbando diferenças regionais relativas à capacidade técnica, a acúmulo de informações, e até mesmo à capacidade política de dirigentes.

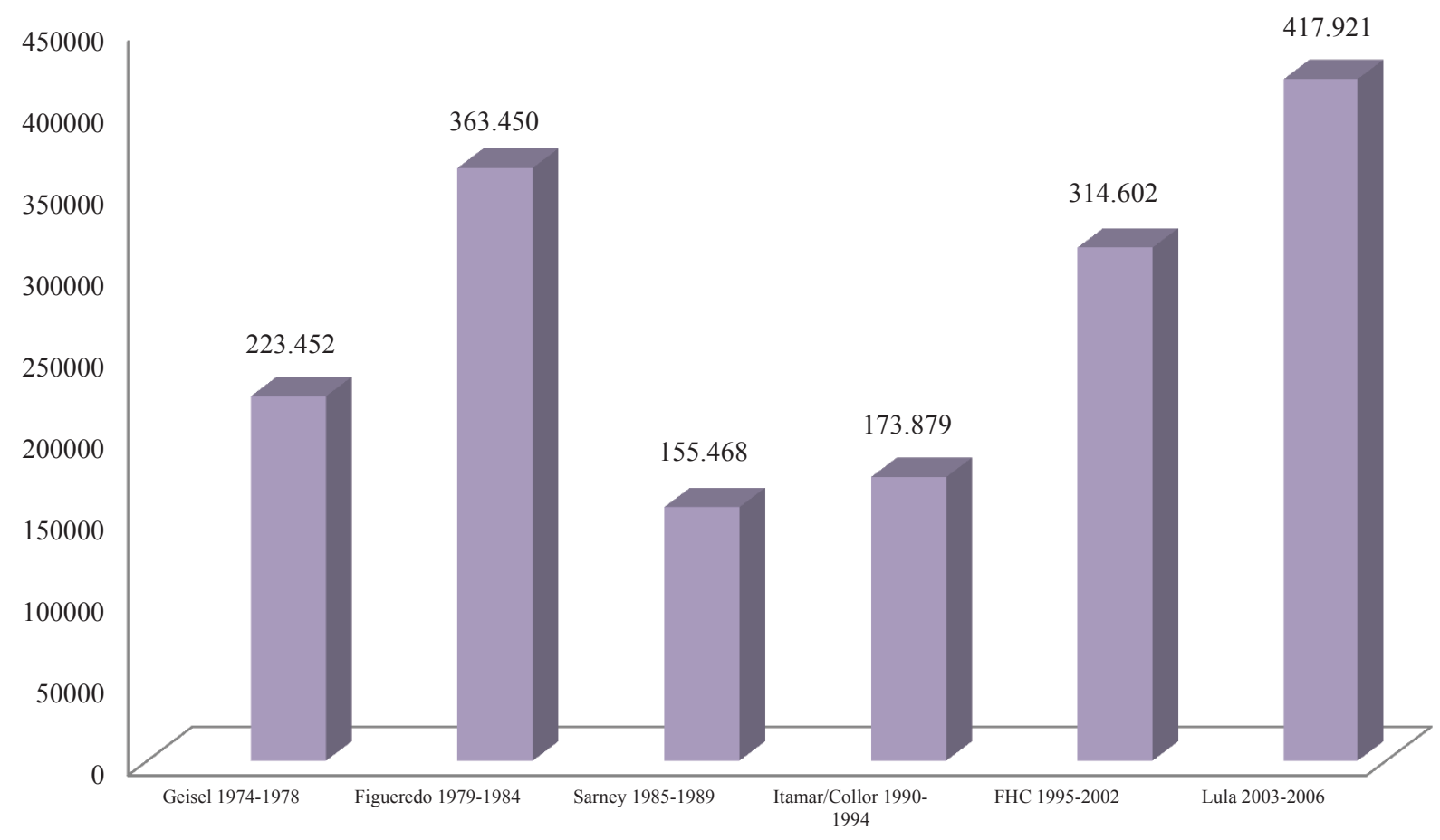

Figura 2 - Gráfico da produção de Habitação financiada (média unidade/ano/governo) pelo Governo Federal entre 1974 e 2006.

Fonte: Universidade Corporativa da Caixa, 2007.

Uma avaliação do quanto tais contradições comprometem o potencial de avanço, em direção à tão almejada integração de escalas, e da sincronia entre o tempo político e o tempo necessário 
para a construção democrática dos processos, ainda é prematura. Mas certamente a compreensão do processo em curso contribuirá para que se tome a integração como meta possível no médio prazo, na medida em que surjam as respostas para os impedimentos existentes atualmente. Apostar no contrário, seria acreditar que há intenção deliberada de sustentar exceções às políticas urbanas construídas no âmbito das Conferências Nacionais das Cidades, e julgar que uma gestão que criou instâncias participativas e alocou recursos para investimentos em setores fundamentais para a sociedade brasileira: habitação, saneamento, geração de emprego e renda, etc., em nada se diferencia das anteriores . Deste ponto em diante, exploraremos os impedimentos constatados a partir de experiências concretas para contribuir para um debate que deve ser travado no presente. No futuro, a história dirá o que os brasileiros foram capazes de construir a partir das possibilidades que temos hoje.

A experiência internacional demonstra que, a partir dos anos 1970, houve uma mudança de paradigma, que elevou o setor habitacional ao mesmo nível de outras indústrias e da agricultura, e que os países desenvolvidos e em desenvolvimento seguiram trajetórias bastante diversas (ex: EUA, Tigres Asiáticos, países latino americanos). As posições assumidas pelas agências multilaterias, os eventos internacionais que levaram à pactuação de compromissos entre países, as agendas e declarações assumidas pela comunidade internacional, juntos contribuíram para a disponibilização de recursos para o setor habitacional. Além disso, houve o reconhecimento da necessidade de políticas públicas e de estrutura institucional com suporte fundamental aos investimentos, garantindo-lhes também o sucesso no combate à pobreza e desigualdade (TIBAIJUKA, 2009). Esse ponto é importante evidenciar a necessidade de persistência da sociedade brasileira na articulação entre políticas públicas e investimentos realizados.

Tibaijuka (2009:92-100) sugere um possível círculo virtuoso criado a partir da adoção da indústria da construção civil como ferramenta econômica: o acesso físico à habitação, com solidez estrutural e bom desempenho ambiental, reduz a mortalidade, amplia a expectativa de vida, melhora a acessibilidade à infraestrutura social e física, e às oportunidades de emprego. Estes fatores, por sua vez, aumentam o bem-estar, a produtividade e o fluxo da renda, e quanto mais alto o fluxo de renda dos domicílios, mais alta a margem de poupança, se tudo for mantido constante. A mesma autora destaca ainda que os países mais ricos tendem a gastar mais em termos absolutos e a destinar uma parcela maior de sua renda nacional para atividades ligadas à habitação e construção civil do que os países pobres. Por outro lado, ela demonstra que os pobres em países em desenvolvimento gastam até $40 \%$ de sua renda doméstica em aluguel, tornando o setor habitacional uma área importante para a geração de renda. Esse nicho de mercado foi explorado por construtoras transnacionais que se tornaram importantes agentes em economias emergentes da Ásia (Hong Kong, Coreia do Sul, Taiwan, Cingapura e Tailândia), adotando a habitação como clara estratégia de crescimento econômico, em que a propriedade da terra assumiu um ponto central, e o sistema de mercado se encarregou de mobilizar recursos, pelo menos para aqueles que podem pagar.

A recente utilização da construção civil como ferramenta de desenvolvimento no Brasil

Em janeiro de 2007, o Decreto no. 6.025 instituiu o Programa de Aceleração do Crescimento e seu comitê gestor. O decreto informa que o programa é constituído de medidas de estímulo ao investimento privado, ampliação dos investimentos públicos em infraestrutura, visando à melhoria da qualidade do gasto público e ao controle da expansão dos gastos correntes no âmbito da Administração Pública Federal. O detalhamento e o posterior monitoramento do programa foi delegado ao Comitê Gestor do PAC, composto pelos ministros da Fazenda, do Planejamento, Orçamento e Gestão e pelo Chefe da Casa Civil, seu coordenador.

O mesmo decreto criou o Grupo Executivo do PAC, composto pela Subchefia de Articulação e Monitoramento da Casa Civil da Presidência da República; pela Secretaria de Orçamento Federal do Ministério do Planejamento, Orçamento e Gestão; Secretaria de Planejamento e Investimentos Estratégicos do Ministério do Planejamento, Orçamento e Gestão; e pela Secretaria de Acompanhamento Econômico do Ministério da Fazenda. A esse grupo caberia consolidar as ações do CGPAC, 
estabelecer metas, acompanhar os resultados da implementação do programa em reuniões periódicas com todos os seus executores (estaduais e municipais). Tal formatação revela o caráter estratégico da iniciativa e a prevalência de motivações econômicas.

O governo federal divulgou que a proposta expressa um novo conceito de investimento em infraestrutura que, associada a medidas econômicas, estimularia o setor produtivo, ao mesmo tempo em que levaria benefícios sociais a todas as regiões brasileiras, indicando um alvissareiro potencial de atuação multiescalar. Tal potencial de articular ações realizadas na escala regional com ações municipais, poderia mudar o papel das cidades nos processos econômicos regionais, e consolidar a tendência de hierarquização da rede urbana brasileira, mas que não se realizou de todo, especialmente nas Amazônia, onde os cortes populacionais definidos para o acesso a recursos para as obras de maior porte não alcançaram os municípios mais afetados por fluxos migratórios decorrentes de atividades econômicas associadas à mineração.

Os investimentos programados para quatro anos totalizam $\mathrm{R} \$ 503,9$ bilhões, organizados em três eixos: infraestrutura logística, infraestrutura energética, e infraestrutura social e urbana. Este último eixo engloba justamente as áreas de saneamento, habitação, metrôs, universalização de energia elétrica e recursos hídricos, que em grande parte convergem para o escopo da PNDU. O terceiro eixo recebeu alocação de $\mathrm{R} \$ 170,8$ bilhões, com a meta de beneficiar 4 milhões de famílias com habitações, 22,5 milhões de domicílios com acesso à água tratada e coleta de esgoto .

A princípio apenas dois grandes programas foram disponibilizados para o enquadramento dos projetos: o PPI e a Urbanização Integrada, enquanto outras formas de acesso a recursos foram mantidas de períodos anteriores, e prosseguia a implantação do Fundo Nacional de Habitação de Interesse Social - FNHIS, principal instrumento de operação do Sistema Nacional de Habitação de Interesse Social, criado em 2005. A diferença de origem deixou os recursos do PAC externos às discussões do Conselho das Cidades, que gerou articulações em conselhos estaduais exigindo a submissão das propostas do PAC aos mesmos, exemplo seguido pelo Conselho Nacional no mês de outubro de 2010 (NEGRÃO et al., 2010). Esta convergência é necessária, e oportuna, visto que o objetivo político da garantir a sucessão da gestão atual já foi alcançado, e o acúmulo de quatro anos de experiência do programa, permitiu a identificação e solução, em alguma medida, de muitos dos problemas operacionais detectados; pressupõe-se então que a partir dai haja espaço para a reavaliação e aperfeiçoamento da sistemática de investimentos e de sua progressiva aproximação aos objetivos da PNDU.

Após a criação, em 2009, do programa Minha Casa Minha Vida, versão do PAC Infraestrutura Social e Urbana a ser operada pelo setor privado, os demais programas existentes voltados para a construção de moradia foram incorporados à sistemática de monitoramento do PAC que, atualmente, conta com várias classes de programas voltados para a produção de habitação de interesse social, contratados por repasse ou financiamento (quadros 1 e 2). Observa-se que há muitas possibilidades de organização do acesso de beneficiários aos recursos destinados para domicílios com renda entre 0 e 3 salários mínimos, permitindo que vários segmentos (setor público, setor privado e terceiro setor) se habilitem para acessá-los. Nessa perspectiva há ênfase à democratização do acesso aos recursos, mas ainda não houve amadurecimento desse potencial, uma vez que o terceiro setor ou segmentos organizados da sociedade civil ainda estão desarticulados de uma rede que lhes garanta assistência técnica, para definição de agendas, de diagnósticos, de propostas, ou ações integradas de planejamento, que deveriam ocorrer antes do acesso ao recursos, a exemplo de práticas de planejamento comunitário já correntes em outros países (WATES, 2006). Na região Norte, a disponibilização de recursos ocorreu antes da discussão de prioridades ou de formatos que fossem mais adequados ao público-alvo em questão, favorecendo a adoção de fórmulas consideradas bem sucedidas a partir prioritariamente dos critérios da produção.

Por outro lado, a liberação de recursos se mantém organizada a partir das demandas espontâneas, e por conta disso permanece a desarticulação entre as diretrizes de desenvolvimento que 
CARDOSO, A. C. D.

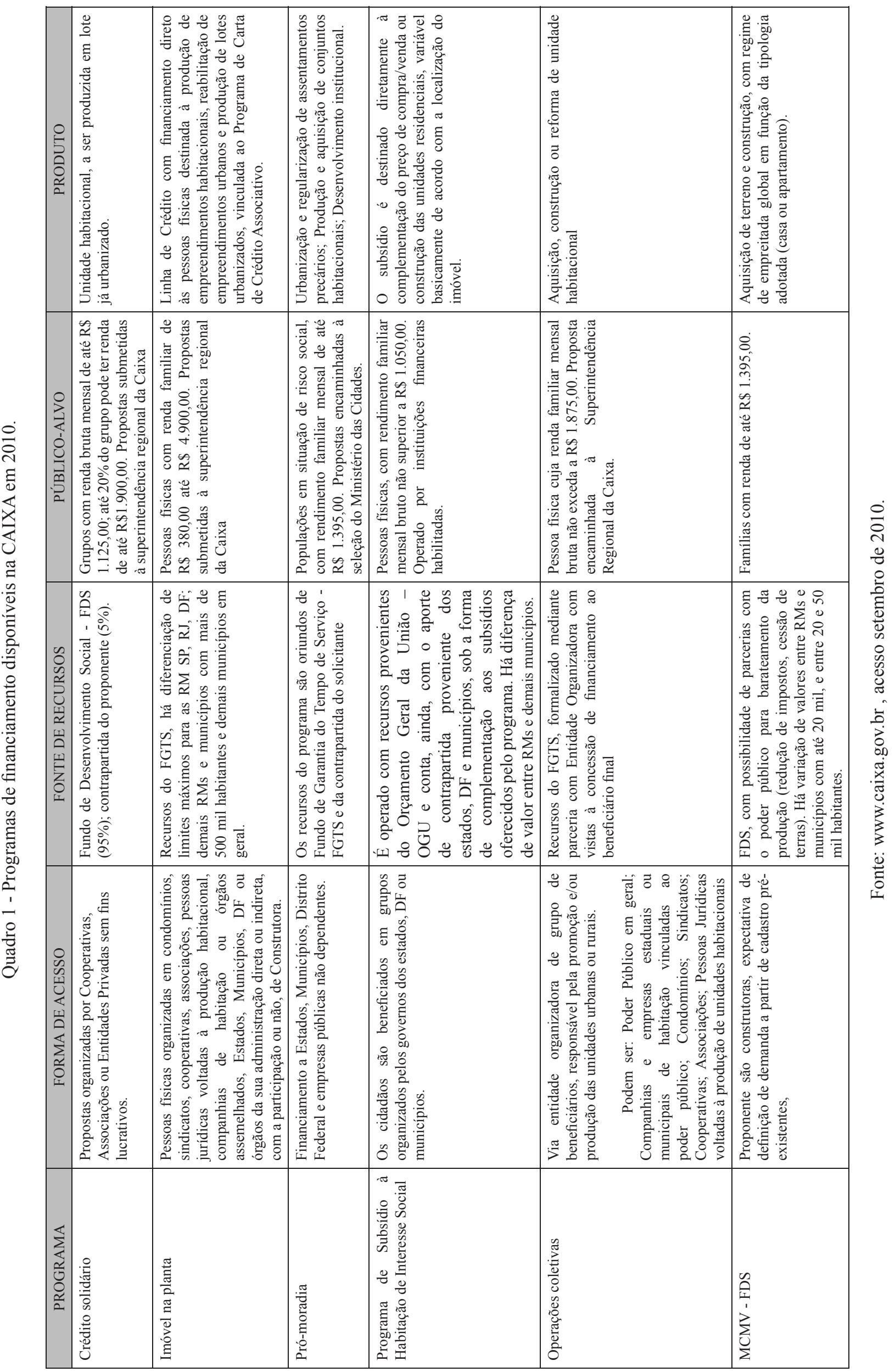




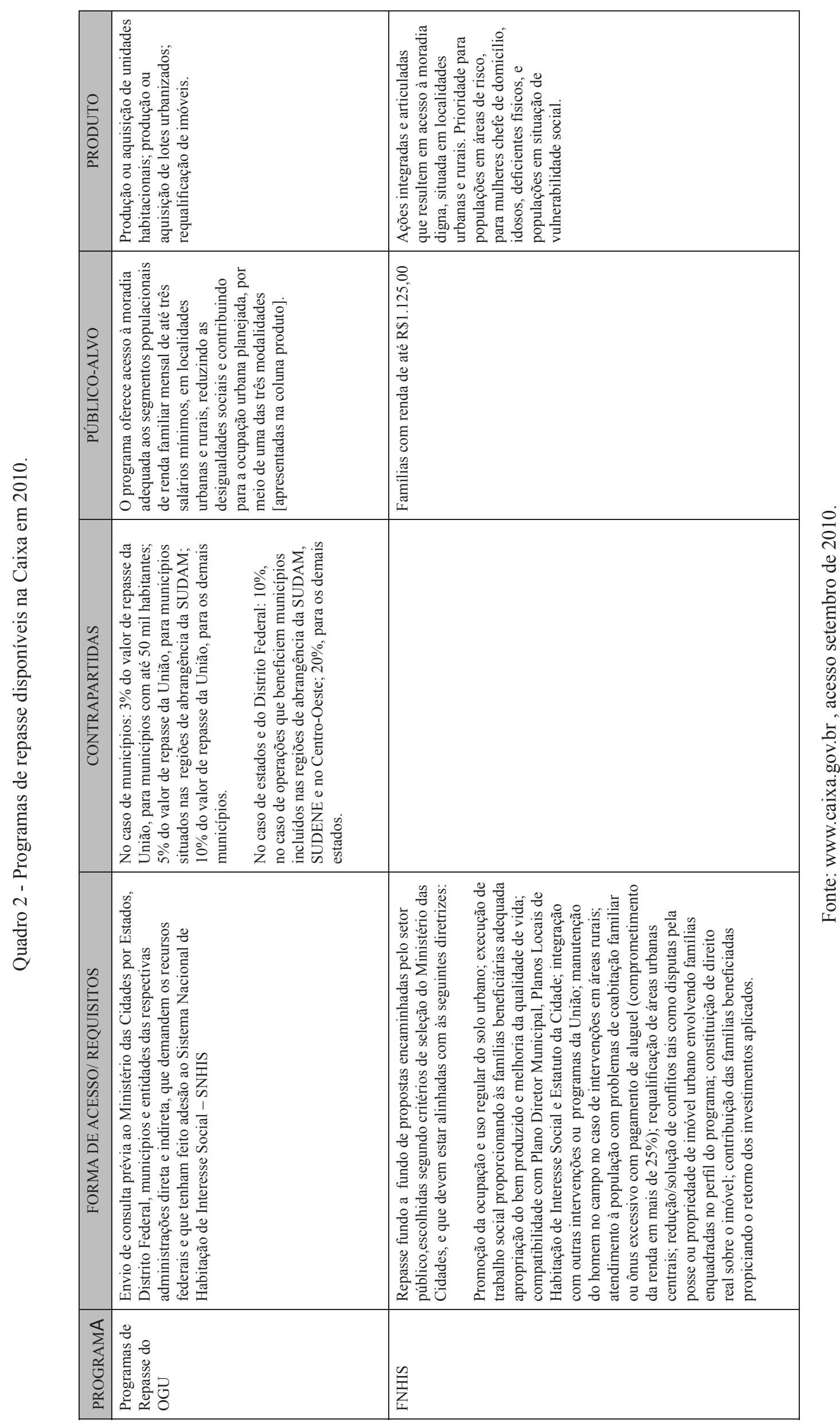


o próprio governo federal estabelece para a escala regional e o investimento que ele promove nas cidades, como se as cidades ainda fossem aquelas cidades da colônia, sem função econômica, ou cuja economia urbana seria tomada como irrelevante pelos pesquisadores e gestores que focam o espaço regional. Além da dificuldade de articular as escalas, restam ainda como desafios a capacidade técnica, a qualidade dos projetos propostos para os empreendimentos habitacionais, a capacidade de integração dos assentamentos à cidade, ou a consciência do seu impacto para a mesma .

Um caso concreto: a contratação do PAC Infraestrutura social e urbana pelo Governo do Estado do Pará

Os problemas apontados na primeira sessão deste texto relativos à operação do PPI, procuram entender porque o aparato de monitoramento assumiu tanta importância para o governo federal. Na primeira geração de contratações da modalidade infraestrutura social e urbana do PAC, a contratação foi desencadeada a partir da apresentação de projetos básicos à Caixa (para ações de saneamento), e ao Ministério das Cidades, para as demais ações (recuperação de assentamentos precários, urbanização integrada), que deveriam atender aos requisitos da Lei federal 8666/93, aplicável para a realização dos processos licitatórios das obras. $\mathrm{O}$ volume e a natureza dos recursos exigiam que fossem realizadas concorrências públicas, e no decorrer do tempo de publicação dos editais era esperado que os projetos sofressem maior detalhamento, e que fosse obtida a licença prévia, aplicável ao processo licitatório pela legislação ambiental.

No caso das propostas apresentadas pelo Governo do Estado do Pará, observou-se que muitos projetos encontrados engavetados nas companhias de saneamento e habitação precisavam ser reelaborados por diversas razões, erro no levantamento topográfico, problemas na delimitação de áreas a serem desapropriadas (passo obrigatório), falta de informação sobre obras inconclusas que seriam retomadas, inadequação da proposta original ao contexto socioambiental existente, obsolescência técnica. Havia um incentivo à proposição de soluções de esgotamento sanitário, e neste setor não existiam projetos, visto que os raros projetos em acervos eram sempre dirigidos para ações corriqueiras de investimento. A disputa política pelos recursos tornava imperiosa a apresentação do material disponível, e tal fato inviabilizou um debate mais amplo a respeito das áreas a serem beneficiadas e da formulação de soluções compatíveis com as expectativas das comunidades beneficiária, gerando as tensões posteriores já apontadas no início do texto.

O licenciamento ambiental gerou outra corrida contra o tempo. A condição alagada das áreas, a existência de população estabelecida no lugar e a intensidade de transformações propostas demandaram estudos complexos para avaliação de impacto ambiental, que precisaram ser feitos em tempo reduzido. O debate entre técnicos ambientais e de outras áreas foi árduo, sempre conduzido a partir de perguntas do tipo: o que é mais adequado, a preservação do meio ambiente insalubre ou a sua transformação para melhorar as condições de vida de seus habitantes? Diante de tais argumentos as licenças eram negociadas mediante muitas cláusulas condicionantes a serem atendidas progressivamente pelos executores, e que, se não satisfeitas, inviabilizavam os estágios posteriores de licenciamento (por exemplo: licença de instalação, por ocasião do início das obras, e de operação, aplicável à operação das redes de saneamento).

O ideal seria que as áreas fossem selecionadas a partir de um diagnóstico que definisse critérios de prioridade, possivelmente a partir do plano diretor do município, em que as mesmas tivessem sido objeto dos estudos exigidos para licenciamento ambiental, e a partir daí ocorresse o desenvolvimento de projetos, de preferência alimentados por debates com a comunidade a ser beneficiária. Mas nessa ordem os contratos só seriam assinados um ano depois, e haveria pouco aproveitamento político do processo para a disputa eleitoral realizada em 2010. Tal experiência deixou evidente a necessidade de estímulo à elaboração de projetos por estados e municípios, o que foi introduzido no PAC 2 , negociado no decorrer de 2010. Agora, diante dos recursos disponíveis, caberia aos estados e municípios interessados, perseguirem uma abordagem compatível com os objetivos da PNDU na elaboração dos novos projetos. 
Outra frente digna de atenção é a do projeto social. A proposta de multidisciplinaridade de abordagem dos contratos não gerou uma carreira para técnicos da área social, a exemplo da carreira de engenheiros e arquitetos, na estrutura organizacional da Caixa. Profissionais com formação superior nas áreas sociais ou sociais aplicadas, concursados na instituição para a função de escriturário de agências, se submetem a uma concorrência para atuar na área social. Há apenas um ano foi criada a supervisão de equipe social, e todas as dificuldades decorrentes dessa "falta de tradição" são somadas ao fato de que tudo o que não era obra, tornou-se objeto da atenção da equipe social. A desestruturação do setor também ocorre fora da Caixa, face ao pequeno número de empresas habilitadas para participar das licitações para contratação desse tipo de trabalho.

Os $2 \%$ do valor do contrato, destinados à implementação do trabalho social, tornaram-se insuficientes diante dos problemas encontrados no dia a dia das obras. Os assentamentos precários correspondem a áreas com elevado índice de violência, com ocorrência de tráfico de drogas, o que dificultou bastante o já complicado processo de acomodação das reivindicações das famílias beneficiadas quanto a processos de aluguel temporário, indenizações, negociação de enquadramento para o benefício (discussão entre proprietários e inquilinos dos barracos, e com pequenos comerciantes). Toda a dimensão social do processo aflorou, explicitando diversas frentes de atuação, relacionadas à microeconomia local e a estratégias de geração de renda, à abordagem das redes sociais existentes por ocasião da distribuição das famílias, à interlocução com lideranças políticas da comunidade, à capacitação para a gestão ambiental da área, ao enfrentamento da violência latente contra empregados da empresa executora e funcionários públicos, deixando as assistentes sociais com a impressão de que o trabalho delas estava sempre aquém do necessário.

$\mathrm{Na}$ realidade toda a dimensão imaterial dos assentamentos precários foi exposta, e ninguém podia supor a extensão do problema até a entrada em campo. A expectativa de que o trabalho social trataria prioritariamente de capacitação da comunidade, da solução de conflitos por relocação ou remanejamento temporário das famílias, ou da negociação de articulação entre setores públicos para provisão de equipamentos, mostrou-se romântica diante do desafio de pactuar condições de urbanidade e garantir de acesso à cidade no sentido mais amplo.

Tal necessidade motivou a alocação de recursos na proposta do PAC 2, para execução de equipamentos sociais em áreas objeto de intervenções em andamento do PAC ou MCMV. Espera-se que a alocação de recursos seja compatível com a demanda, e novos passos sejam dados para solução dos desafios de segurança pública, geração de emprego e renda, gestão ambiental e articulação das áreas com suas adjacências, pela convergência de recursos de outras políticas públicas e efetivação da presença do Estado em áreas onde outrora essa presença não existia. Se esse for o caminho assumido, teremos iniciado um processo de consolidação social e espacial a partir do aproveitamento máximo dos recursos públicos.

Apontamos a necessidade de investigação de estratégias para a inclusão econômica da população beneficiada pelos investimentos do PAC e MCMV, utilizando a cidade e a habitação com parte do processo.

Experiências consagradas como a de Muhammad Yanus, premiado com o Nobel da Paz em 2006, pela criação e condução do Banco Grameen precisam ser visitadas por algum segmento da sociedade ou do governo brasileiro, para que o investimento em obras efetivamente resulte na inclusão social das comunidades beneficiadas. Além disso, é fundamental a continuidade dos investimentos com foco na máxima ampliação dos benefícios, para que as mudanças físicas não promovam apenas a diferenciação das novas áreas infraestruturadas e sua integração ao mercado imobiliário formal; caso em que ocorrerá a expulsão das famílias e reinício do ciclo de informalidade e exclusão, no sentido inverso aos objetivos da PNDU.

Por fim, lembramos dos limites da capacidade administrativa da máquina pública, apontando que, no caso pesquisado, apenas $40 \%$ das ações contratadas foram executadas no decorrer dos quatro anos, sem que houvesse problemas de repasse de recursos pelo governo federal além dos observados 
e resolvidos dentro da sistemática de operacionalidade do CGPAC. Ficou evidente que o ritmo e a quantidade das obras esperados, estavam acima da capacidade de empresas (de projeto, empreiteiras, de execução do trabalho social, de material de construção) e de órgãos públicos naquele contexto. Muita investigação ainda precisa ser realizada para explicar esse fato no Pará e observá-lo à luz da experiência de outros estados para que também isso seja considerado pela concepção do programa e pelas políticas públicas a ele associadas, daqui por diante.

Considerações finais: uma agenda para aperfeiçoamento das experiências oficiais recentes

Diante do exposto, consideramos oportuno elencar alguns pontos desafiadores que merecem atenção e que, se devidamente tratados, poderão desencadear um ciclo virtuoso sem precedentes na gestão de investimentos em áreas urbanas no Brasil.

1. Necessidade de produção de conhecimento para permitir a associação de diretrizes e estudos sobre carteiras de investimentos formulados para a escala regional, com os investimentos contratados para as áreas urbanas.

2. Necessidade de desenvolvimento de estratégias de gestão pública que permitam a coordenação de políticas setoriais e a ação casada dos entes federados para aceleração dos processos de inclusão socioespacial da população pobre.

3. À luz da experiência dos programas recentes, revisar a estrutura organizacional e as missões assumidas pelo Ministério das Cidades e Caixa, de modo a detectar lacunas e providenciar instâncias competentes para preenchê-las, no sentido de maximizar o benefício do investimento público para o usuário final, de modo a definir mais claramente a identidade da Caixa como banco, e implementar a coordenação de políticas urbanas setoriais pelo Ministério das cidades.

4. Definir claramente as competências dos entes federados no processo em tela, criar um marco institucional para a gestão metropolitana e planejar a integração das ações técnicas e políticas com os canais instituídos de participação popular, de modo a consolidar a democracia e respeitar a diversidade socioeconômica, cultural e ambiental do país.

5. Aproximar urbanistas, profissionais das áreas de engenharia e social, dos economistas dedicados à microeconomia para que sejam formuladas soluções sustentáveis que contemplem oportunidades de geração de renda tanto quanto acesso à moradia.

6. Assumir as cidades como recursos estratégicos, para a redução das desigualdades entre as regiões brasileiras e consolidação do papel do Brasil no continente sul americano.

\section{AGRADECIMENTO}

A autora agradece o apoio viabilizado pelo CNPq, através de bolsa de produtividade de pesquisa, a revisão do texto por Lais Zumero, e a colaboração das equipes técnicas da GIDUR/ Belém, da COHAB/ Pará, e da Câmara Setorial de Infraestrutura da extinta Secretaria de Estado de Governo do Pará.

\section{REFERÊNCIA BIBLIOGRÁFICA:}

ARRETCHE, Marta. Federalismo e Políticas Sociais no Brasil: problemas de coordenação e autonomia. São Paulo em Perspectiva. São Paulo: 2004. Disponível em < http://www.enap.gov.br/index.php?option=com docman\&task=doc_view\&gid=2866 $>$. Acesso em setembro de 2010.

BHATT, Vikram; SCRIVER, Peter. After the masters, Contemporary Indian Architecture. Ahmedabad: Mapin Publishing, 1999, 89-103.

BONDUKI, N. Origens da Habitação Social no Brasil. São Paulo: Estação Liberdade, FAPESP, 1998. 
BRASIL. Decreto Federal no. 6025, de 22 de janeiro de 2007. Institui o Programa de Aceleração do Crescimento - PAC, o seu comitê gestor, e dá outras providências.

BRASIL. Ministério das Cidades/ SNH. Assentamentos Precários no Brasil Urbano. Brasília: MinCidades/SNH, 2007. Arquivo pdf disponível em http://www.cidades.gov.br/secretarias-nacionais/secretaria-de-habitacao/arquivos/Assentamentos\%20Precarios\%20no\%20Brasil\%20Urbano.pdf

BRASIL. Ministério das Cidades. Plano Nacional de Habitação. Brasília: MC/SNH, 2009.

BRASIL. Ministério das Cidades. Política Nacional de Desenvolvimento Urbano. Cadernos 1. Brasília: Ministério das Cidades, 2004.

BRASIL. Ministério das Cidades. Tipologia das Cidades. Como Andam as Regiões Metropolitanas. Coleção Estudos e Pesquisas do Programa Nacional de Capacitação das Cidades. Brasília: Ministério das Cidades, 2008. Vol.2.

BRASIL. Conselho das Cidades. Texto Base da $4^{\text {a }}$ Conferência Nacional das Cidades. Brasília: MinCidades, 2010. Arquivo pdf.

CARDOSO, Adauto. Contextualização/Caracterização. In: Brasil. Ministério das Cidades/ Secretaria Nacional de Habitação. Política Habitacional e a integração urbana de assentamentos precários. Parâmetros conceituais, técnicos e metodológicos. Brasília: MinCidades/SNH, 2008, pp. 13-46.

CARDOSO, Ana. O Espaço Alternativo, vida e forma urbana nas baixadas de Belém. Belém: EdUfpa, 2007. CARDOSO, Ana. O problema das escalas e o desafio do urbano na Amazônia Oriental. Anais do I ENANPARQ. Rio de Janeiro: ANPARQ, 2010. Cd-rom.

CARDOSO, Ana; MONTEIRO, Miguel. O (des) conhecido urbano Amazônico contemporâneo. Texto submetido para publicação. 2010 (mimeo).

CARPINTÉRO, M. A Construção de um Sonho. Campinas: Editora da Unicamp, 1997.

HALL, P. Cidades do Amanhã. São Paulo: Perspectiva, 1995.

HARVEY, David. A Justiça Social e a Cidade. São Paulo: Hucitec, 1980.

HARVEY, David. A produção capitalista do espaço. São Paulo: Annablume, 2005.

IPEA. Instituto de Pesquisa Econômica Aplicada. Série Gestão do Uso do Solo e Disfunções do Espaço Urbano. Brasília: IPEA, 2001. 6 volumes.

JATOBÁ, Jorge. Desenvolvimento Regional no Brasil: políticas e controvérsias. In: SAYAD, João; LOPES, Francisco. (orgs) Resenhas de Economia Brasileira. São Paulo: Saraiva, 1979.

MARICATO, Ermínia. As idéias fora do lugar e o lugar fora das idéias. Planejamento urbano no Brasil. In: A Cidade do Pensamento Único. Vozes, Petrópolis, 2002, p. 89-103.

MARICATO, Ermínia. Brasil, Cidades - Alternativas para a crise urbana. Petrópolis: Vozes, 2001.

MIRANDA, Lívia; CARDOSO, Ana; SANTORO, Paula. Mesa Redonda “A questão periurbana no Brasil e os desafios de sua tradução em agenda política pelo direito à cidade. In: Seminário Nacional As interfaces urbano-regional e urbano-rural na Política Nacional de Desenvolvimento Urbano: reflexões sobre o periurbano no Brasil. Fórum Social Urbano. Rio de Janeiro: FASE, 25 de março de 2010.

NEGRÃO, Marcília et al. O Novo Arranjo Institucional da Política Habitacional no Pará: avanços e limites nos espaços de controle social. Anais do II Encontro da Sociedade Brasileira de Sociologia da Região Norte. Belém: UFPA, 2010. Disponível em http://www.sbsnorte2010.ufpa.br/site/anais/index.html.

OLIVEIRA, Francisco. O Estado e a Exceção ou o Estado de Exceção? R. B. Estudos Urbanos e Regionais, v5, n1, maio 2003, pp. 9-14.

RIBEIRO, Luiz Cesar de Q. CARDOSO, Adauto Lucio (org). Reforma urbana e gestão democrática: promessas e desafios do Estatuto da Cidade. Rio de Janeiro: Revan/FASE, 2003.

ROLNIK, Raquel. A Cidade e a Lei. São Paulo: Nobel, 1997.

SINGER, Paul. Economia Política da Urbanização. São Paulo: Brasiliense, 1973

TIBAIJUKA, Anna. Building Prosperity, Housing and Economic Development. London: Earthscan, 2009. VALENCA, Márcio. M. . Habitação: Notas sobre a natureza de uma mercadoria peculiar. Cadernos Metrópole (PUCSP), São Paulo, n. 9, 2003, p. 165-171. 
VALENÇA, Márcio; BONATES, Mariana. The trajectory of social housing policy in Brazil: From the National Housing Bank to the Ministry of Cities. Habitat International, 34 (2010), 165 - 173.

WATES, Nike. The Community Planning Handbook. How People can shape their cities, villages and towns in any part of the word. London: Earthscan, 2006.

Sítios da wide world web consultados:

www.cidades.gov.br/secretarias-nacionais/secretaria-de-habitacao/

www.caixa.gov.br

www.cabe.org.uk

www.brasil.gov.br/pac

www.grameen.foundation.org

http://www.planalto.gov.br/ccivil_03/Leis/L8666cons.htm

http://itcpfgv.org.br/blog/financas-solidarias/banco-bem-empresta-630-mil-em-credito-habitacional/

Trabalho enviado em maio de 2011

Trabalho aceito em agosto de 2011 